\title{
Urban Rehabilitation of the Unirii Square in Cluj-Napoca
}

\author{
Alex-Péter COTOZ, Valentin-Sebastian DAN, Maria CANTOR* \\ Department of Horticulture and Landscape Design, University of Agricultural Sciences and Veterinary \\ Medicine Cluj-Napoca, 3-5 Manastur St, Romania \\ *corresponding author: marcantor@yahoo.com
}

BulletinUASVM Horticulture 77(1) / 2020

Print ISSN 1843-5254, Electronic ISSN 1843-5394

DOI:10.15835/buasvmcn-hort: 2019.0010

\begin{abstract}
To improve the design of the Unirii Square from Cluj-Napoca both aesthetically and functionally, principles of urban landscape and sustainable design were implemented. To achieve this goal, modular and mobile structures with two different types of low maintenance plant species, Sedum and Cornus were selected. These species have been chosen because of their ecological benefits, hardiness attributes and morphological characteristics. This paper aims to present an urban green component adaptable to different scenarios such as major annual events without interfering with temporary constructions and pedestrian routes while at the same time creating a more aesthetic and attractive open space for locals and tourists alike. Every element added to the square can be relocated or moved at any given time without negative impact to the environment. To present the potential of this design concept, three different arrangement design scenarios were conducted - one for the everyday life of the public and the other to accommodate the unfolding of two major events held annually: the TIFF film festival and the Christmas fair.
\end{abstract}

Keywords: landscape design, low maintenance, modular, sustainable, urban

\section{Introduction}

Urban spaces occupy an essential role in people's everyday life, regardless of the size, placement and economic status of an urban landscape. Green infrastructures can reduce health issues such as mental fatigue, depression and stress (Kaplan, 1993; Kaplan 1995; Mooney 1992; Ulrich, 1991), social behavior and economic growth, all of which can lead to a healthy development of the city (Lee, 2011).

Sustainable design must retain and respect as many functional elements of a site as possible while at the same time consider the relationship between the place and the community itself. It presumes the mindful use of environmentally friendly materials and native, drought tolerant types of vegetation that require low maintenance (Russ, 2009).

Green infrastructure design minimizes the affected area by reducing pollution loads in surface water, reduces heat island effects, increases biodiversity, improves the infiltration of groundwater, improves the air quality (Fairbrass, 2018) and has a positive influence on the human psyche (Lee, 2011).

This concept design aims to create a green space adaptable to the needs of the citizens and for hosting different events by using easy to reposition modular and mobile structures, planted with species such as Sedum and Cornus, all of which are 
used in concordance with a previously conducted urban analysis.

\section{Materials and methods}

For this concept design, an urban and visual analysis was conducted, through a period of over two months, from May to June. During every day of the week within a two hour time frame 7:30-9:30, 14:00-16:00, or 20:00-22:00 data were collected and analyzed.

Some of the main problems encountered in this research are:

- Limited resting areas in shaded zones during high temperature days;

- The inability to keep the square's main and secondary pedestrian routes free of obstacles;

- The limited ability to create possible new social activities.

Unirii Square, the central point of the medieval city of Cluj-Napoca, surrounds St. Michael's Church, covering approximately three acres of land.

During cooler days, Unirii Square is used mainly as a transitory route and resting area. In the days with intensive heat it is rather impossible to spend more than a few minutes in the square because of the heat island effect, also the areas that are protected from the sun are limited or nonexistent. Apart from the regularly held cultural events that take place in the square, the area presents very few possibilities for locals and tourists to use it for anything but a transitory space. A survey of existing vegetation numbered 91 trees, positioned both in and around the square, planted randomly or aligned along the sidewalks.

Using principles of both urban and sustainable design, pedestrian routes, plants and structures were specifically chosen and used to create an efficient urban green space.

For an open public space to be attractive (Carmona, 2018), the following design principles must be considered:

- Context - the position within the major local transportation network;

- Activities within the space - the spaces should be designed to host a series of activities at different times of the day or year;

- Microclimate - people search for places that are sheltered by the wind and provide shade on sunny days;

- Scale - must be suitable for the destination depending on the space;

- Objects in the urban space - trees, public art expositions in form of statues, fountains, and structures that can create impromptu gathering places.

To facilitate repositioning of the structures in question, lightweight and durable objects made of plastic reinforced with carbon fiber were used.

Furthermore, the vegetation used for the design, Sedum and Cornus sp. is adaptable to the final scenario because of the durability and low maintenance throughout the year.

Sedum species, are drought tolerant, can absorb, in a period of two years, 375g of carbon/ $\mathrm{m}^{2}$ (Getter et al., 2009), they can reduce the heat island effect in densely built urban areas by up to $9^{\circ} \mathrm{C}$ (Alexandri et al., 2006) and can absorb great amounts of air pollutants (Irga et al., 2019).

The metabolism specific to Sedum sp., the Crassulacean Acid Metabolism, allows these types of species to absorb water and to release it in very small quantities throughout the day (Kluge, 1977).

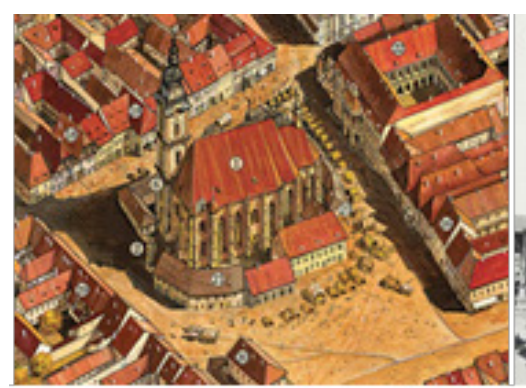

a)

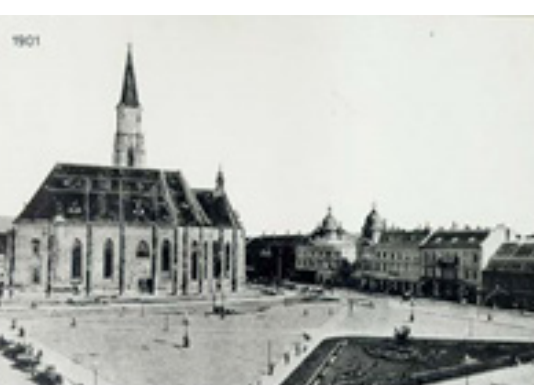

b)

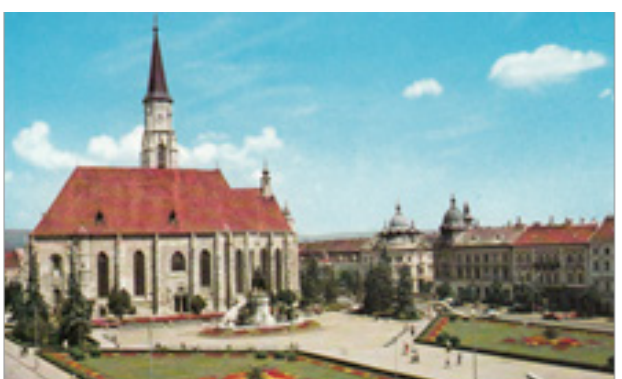

c)

Figure 1. Historical images of Unirii Sqaure: a) 16th - 18th century, b) 19th century, c) 20th century a) http://farm1.static.flickr.com/116/286916682_5c99d6d8a2_o.jpg; b) https://clujcapitala.ro/wp-content/ uploads/2014/08/piata-unirii.jpg; c) https://clujcapitala.ro/wp-content/uploads/2015/01/325_001.jpg 
This gives them the ability to survive and develop in full sun with little to no water.

Cornus species, with a height between 4 and $5 \mathrm{~m}$, present a relatively high drought tolerance (Stoecklein 2001), are adaptable to all types of soil - dry, rich, poor, damp, alkaline, acidic, neutral (Gayraud 2013) and are relatively good pollutant (particulate matter) absorbents.

To understand the historical evolution of the main pedestrian routes and the green areas development of Unirii Square, historical illustrations of three major centuries were used (Fig. 1). It was important to comprehend how the square evolved as a whole and how it gradually and simultaneously developed alongside the public and their needs (Fig. 2).

To understand the functionality of the square, a traffic analysis was conducted. On average, depending on the weather and the day of the week, as presented in Table 1, between 729 and 1516 locals and tourists traverse this square. Out of these, only around $10 \%$ use the square as a resting area - this is because, among other things, limited seating areas (35 benches) and exposure to the weather.

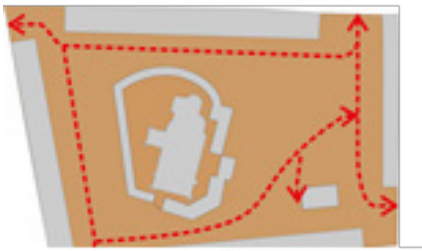

a)

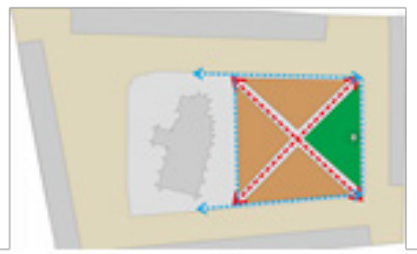

b)

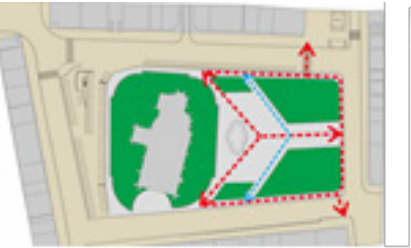

c)

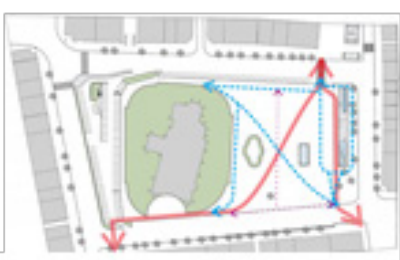

d)

Figure 2. Pedestrian route evolution from the 16 th to the 21 st century a) 16 th -18 th century, b) 19 th century, c) 20 th century, d) 21 st century

Table 1. Pedestrian crossing analysis

\begin{tabular}{|c|c|c|c|c|c|c|c|}
\hline \multicolumn{7}{|c|}{ May-June - time period - 60 days } & \multirow{3}{*}{$\begin{array}{c}\text { Average no. of } \\
\text { pedestrians } \\
2 \text { hours/day }\end{array}$} \\
\hline \multicolumn{3}{|c|}{ General data } & \multirow{2}{*}{$\begin{array}{l}\text { No. of pedes- } \\
\text { trians }\end{array}$} & \multicolumn{3}{|c|}{ Crossing pedestrians } & \\
\hline Sky & $\begin{array}{l}\text { Average } \\
{ }^{\circ} \mathrm{C}\end{array}$ & $\begin{array}{l}\text { No. of } \\
\text { hours }\end{array}$ & & $7.30-9.30$ & $14.00-16.00$ & $20.00-22.00$ & \\
\hline Sunny & 21 & 78 & 48096 & 27003 & 7146 & 13947 & 1233 \\
\hline Cloudy & 15 & 18 & 6558 & - & 6558 & - & 729 \\
\hline Changing & 19.6 & 30 & 22746 & 11298 & 4995 & 6453 & 1516 \\
\hline
\end{tabular}

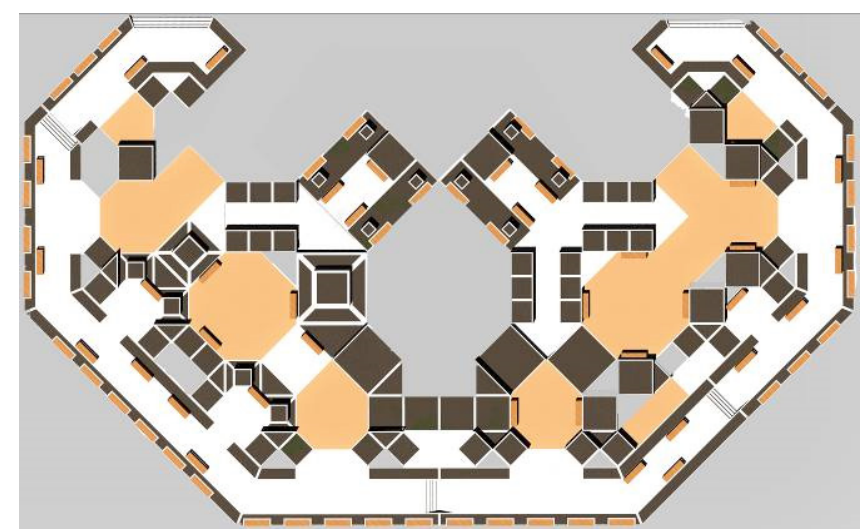

Figure 3. Final structure design 
In order to create an accurate concept design, 3D modeling and rendering programs were used - SketchUp2018, Lumion 6, and vector drawing software CorelDraw 2017.

Topographic plans were processed and the result in the form of a sketch was used as a general guideline for the final design (Fig. 3). In the design process for this concept, a fractal principle was chosen. This principle is based on the repetition of a geometric shape and its dimensional multiples that together facilitate easy methods of combination and rearrangement (Mandelbrot, 1983).

\section{Results and Discussion}

The new design concept includes both modular and mobile containers on wheels which house four types of plant species with different decorative arrangements.

This landscape design (Fig. 4) occupies 1615 $\mathrm{m}^{2}$ out of which $1024 \mathrm{~m}^{2}$ are pedestrian routes, 72 $\mathrm{m}^{2}$ seating areas and $519 \mathrm{~m}^{2}$ dedicated to plants: $490 \mathrm{~m}^{2}$ to Sedum spathulifolium 'Cape Blanco', Sedum spathulifolium 'Purpureum', Sedum spurium 'Fuldaglut' and $29 \mathrm{~m}^{2}$ to Cornus mas (Fig. 5).

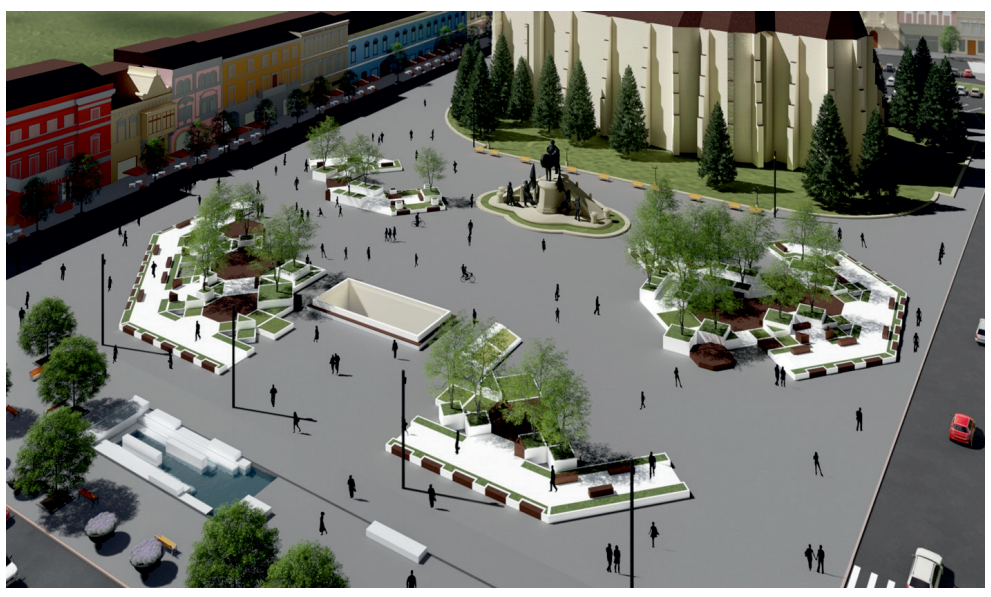

Figure 4. Semi profile view of main structural design

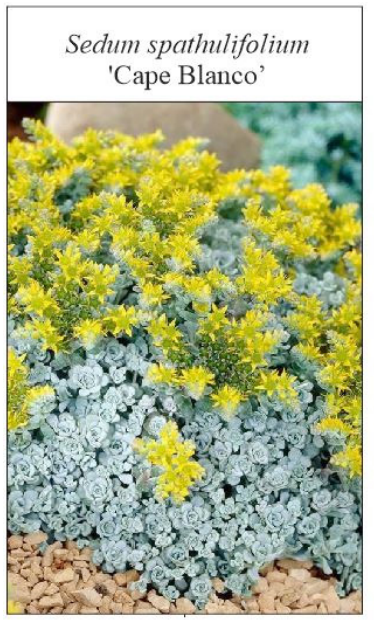

dimensions : color height: $10 \mathrm{~cm}$

width: $>50 \mathrm{~cm}$

exposition

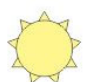

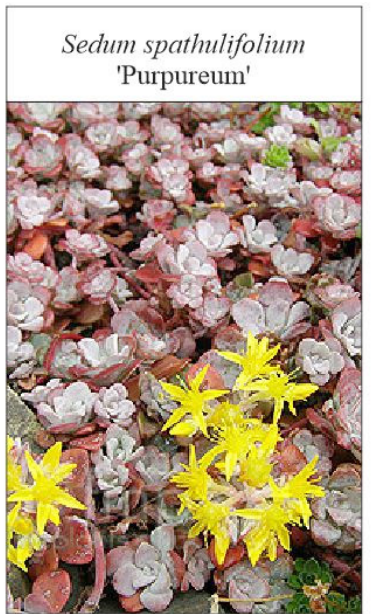

dimensions : color

height: $10 \mathrm{~cm}$

width: $>50 \mathrm{~cm}$

exposition

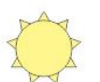

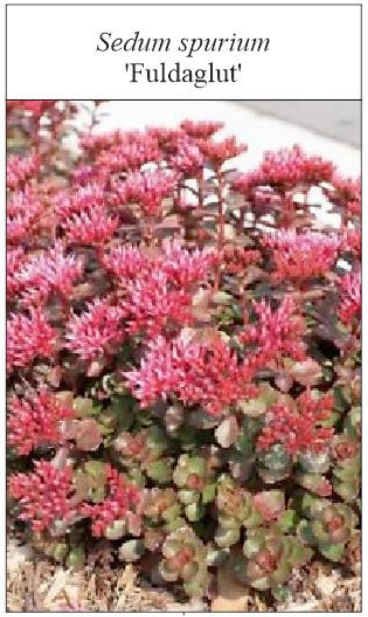

dimensions color

height: $10 \mathrm{~cm}$

width $>50 \mathrm{~cm}$

exposition

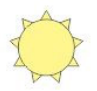

Cornus mas

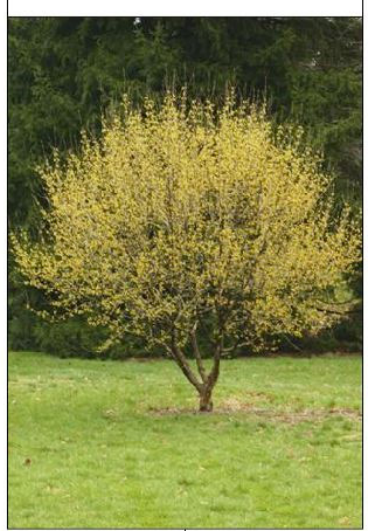

dimensions

height: $2-4 \mathrm{~m}$

width: $2-4 \mathrm{~m}$

exposition

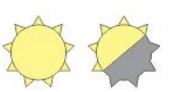

Figure 5. Plant species recommended for the design 
In total, 4.929 plants are needed: 4.900 Sedum, divided equally between the three species mentioned above, planted $10 / \mathrm{m}^{2}$ at a distance of $10 \mathrm{~cm}$ of each other and 29 of Cornus.

The design features six types of units, three of which are highlighted in Figure 6. They vary in size with widths of $1 \mathrm{~m}, 2 \mathrm{~m}$, or $3 \mathrm{~m}$ and a height of $50 \mathrm{~cm}$ or $120 \mathrm{~cm}$, applied to octagonal terraces and pedestrian routes covering a little over 550 $\mathrm{m}^{2}$. In total, there are 154 structures, representing mobile planters, pedestrian routes, terraces, and 80 wooden benches.

The basic shape of the assembly was divided in such a way that the final result presents four distinct areas in the four corners of the square. The reasoning behind the distribution to these specific areas was to avoid obstruction of the two main crossings - from SE to NW and from NE to SW.

All areas have shaded spaces, pedestrian paths, seating places, and with the help of different textures, shapes and colors, a quiet and unique atmosphere can be created for socializing and rest.
The use of this type of design in a densely transited area creates the opportunity for numerous possible design scenarios that provide both decorative areas and generous space for other constructions. Following the achieving of this concept, we can state that the pedestrian routes are not blocked or obstructed in any way, on the contrary, they offer diversity in an otherwise vast and monotonous space. The whole new concept offers continuity, simplicity while at the same time fulfilling the social needs of locals as well as creating an attraction point for tourists. Using easy to reposition modular and mobile structures to house different plant species, an ever-changing urban design has been made possible, adaptable to the needs of the people. To further emphasize the adaptability of this design, two additional scenarios are presented - the TIFF film festival, (Fig. 7, left) and the Christmas fair, (Fig. 7, right).

In these two cases, the modules, highlighted with yellow stripes, were repositioned in such a way that pedestrian routes, newly placed structures such as tents, projection screens, ice rinks, wooden houses etc. would not be obstructed
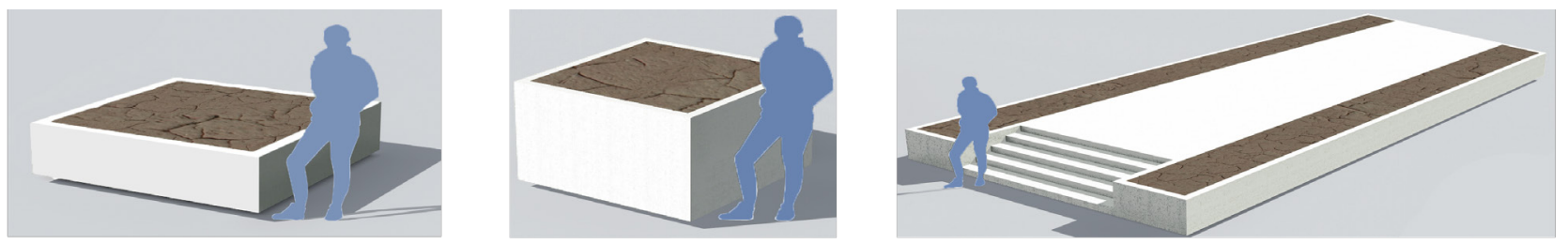

Figure 6. Planter units
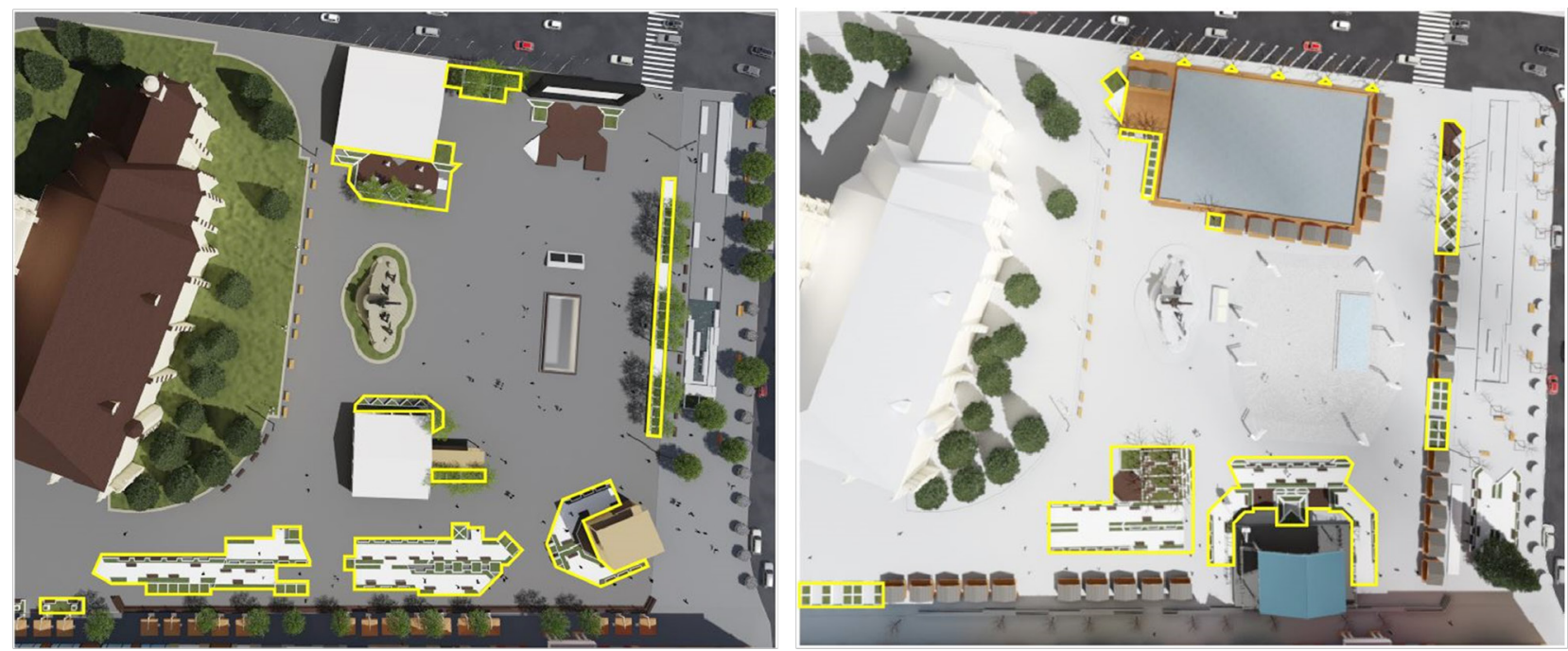

Figure 7. Top view - left TIFF module arrangement, right Christmas fair arrangement 
Table 2. Proposed changes and improvements

\begin{tabular}{|c|c|c|c|c|c|c|}
\hline \multicolumn{4}{|c|}{ Surface area $\left(\mathrm{m}^{2}\right)$} & \multirow{3}{*}{$\begin{array}{c}\text { Carbon } \\
\text { sequestration } \\
\text { potential }\end{array}$} & \multirow{2}{*}{\multicolumn{2}{|c|}{ No. of benches }} \\
\hline \multicolumn{2}{|c|}{ Green area } & \multicolumn{2}{|c|}{ Constructions } & & & \\
\hline existent & added & existent & added & & existent & proposed \\
\hline 4406 & 519 & 26694 & 1096 & $490 \mathrm{~m}^{2} \times 187.5 \mathrm{~g}$ & 35 & 80 \\
\hline \multicolumn{2}{|c|}{$4925=11.8 \%$ growth } & \multicolumn{2}{|c|}{$\begin{array}{l}\text { the same due to the } \\
\text { overlapping materials }\end{array}$} & $91.87 \mathrm{~kg} /$ year & \multicolumn{2}{|c|}{$125=228 \%$ growth } \\
\hline
\end{tabular}

in any way. These modules were used as physical barriers, extensions of concert stages, intimate enclosed areas, green walls using Cornus and geometrically rearranged pedestrian routes.

Due to this type of concept design, potential growth in both pollutant absorption and green areas can be reported (Tab. 2). Carbon sequestration can be improved by up to $92 \mathrm{~kg} /$ year by using only Sedum species and increasing the surface of the green area by $11.8 \%$ the heat island effect can be reduced by up to 2-3 centigrade.

Increasing the number of seated areas by a total of 80 , around 200 more locals and tourists can spend time in a healthier and calming environment.

From an irrigation perspective, the proposed modules are interconnected with holes in such a way that when necessary, water can pass through the walls of the structures.

\section{Conclusion}

Regarding the pedestrian activity, this proposal encourages social interactions and spending as much time as possible in open spaces.

Paying special attention to the entertainment and cultural characteristics of this site, pedestrian routes and materials used, the design intervention of Unirii Square has the aim to emphasize on the social and cultural interaction aspects by creating a new space where people can spend time in a friendlier and more welcoming environment.

This concept is a dynamic and adaptable design, from which elements can be kept or removed. Unirii Square has very few possible and viable options to further elevate and improve its value and this type of green infrastructure can be regarded as one of them. Without being invasive it creates a unique urban landscape for locals and tourists alike. Also, the versatile design can be used in different similar locations if variables such as sunlight, space and geometry are met.

\section{References}

1. Alexandri E, Jones P (2006). Temperature decreases in an urban canyon due to green walls and green roofs in diverse climates. Building and Environment 43(4): 480493.

2. Carmona M (2018). Principles for public spa0ce design, planning to do better. Urban Des Int, 24(1): 1468-4519.

3. Fairbrass A, Jones K, McIntosh A, Yao Z, Malki-Epshtein L, Bell S (2018). Green Infrastructure for London: A review of the evidence A report by the Engineering Exchange for Just Space and the London Sustainability Exchange.

4. Gayraud A (2013). Cornus (Monograph). Giorgio Tesi Editrice, Pistoia.

5. Getter KL, Rowe DB, Robertson GP, Bert M, Creggand J, Andresen A (2009). Carbon Sequestration Potential of Extensive Green Roofs. Environ. Sci. Technol. 43(19):7564-7570.

6. Irga PJ, Pettit T, Irga RF, Paull NJ, Douglas ANJ, Torpy FR (2019). Does plant species selection in functional active green walls influence VOC phytoremediation efficiency? Environmental Science and Pollution Research.

7. Kaplan R (1993). The Role of Nature in the Context of the Workplace. Landscape and Urban Planning 26(1-4) :193201.

8. Kaplan S (1995). The Restorative Benefits of Nature: Toward an Integrative Framework. Journal of Environmental Psychology 15(3): 169-182.

9. Kluge M (1977). Is Sedum acre L. a CAM plant? Oceologia 29: 77-83.

10. Lee A CK (2011). The health benefits of urban green spaces: A review of the evidence. Journal of Public Health.

11. Letter C, Jäger G (2019). Simulating the potential of trees to reduce particulate matter pollution in urban areas throughout the year, Environment, Development and Sustainability.

12. Mandelbrot BB (1983). The fractal geometry of nature, Macmillan, ISBN 978-0-7167-1186-5. 
13. Mooney P, Nicell PL (1992). The Importance of Exterior Environment for Alzheimer Residents: Effective Care and Risk Management. Healthcare Management Forum 5(2): 23-29.

14. Russ TH (2009). Site Planning and Design Handbook, 2nd edition, The McGraw-Hill Companies.
15. Stoecklein MC (2001). The complete plant selection guide for landscape design. Purdue University Press, West Lafayette.

16. Ulrich RS, Simons RF, Losito BD, Fiorito E, Miles MA, Zelson M (1991). Stress Recovery During Exposure to Natural and Urban Environments. Journal of Environmental Psychology 11(3): 201-230. 